Published in final edited form as:

Heart Fail Rev. 2013 September ; 18(5): . doi:10.1007/s10741-012-9340-0.

\title{
Mitochondrial dysfunction in heart failure
}

\author{
Mariana G. Rosca and Charles L. Hoppel \\ Center for Mitochondrial Diseases and Departments of Medicine and Pharmacology, School of \\ Medicine, Case Western Reserve University, Cleveland, Ohio
}

\begin{abstract}
Heart failure (HF) is a complex chronic clinical syndrome. Energy deficit is considered to be a key contributor to the development of both cardiac and skeletal myopathy. In HF several components of cardiac and skeletal muscle bioenergetics are altered, such as oxygen availability, substrate oxidation, mitochondrial ATP production, and ATP transfer to the contractile apparatus via the creatine kinase shuttle. This review focuses on alterations in mitochondrial biogenesis and respirasome organization, substrate oxidation coupled with ATP synthesis in the context of their contribution to the chronic energy deficit, and mechanical dysfunction of the cardiac and skeletal muscle in HF. We conclude that HF is associated with decreased mitochondrial biogenesis and function in both heart and skeletal muscle, supporting the concept of a systemic mitochondrial cytopathy. The sites of mitochondrial defects are located within the electron transport and phosphorylation apparatus, and differ with the etiology and progression of HF in the two mitochondrial populations (subsarcolemmal and interfibrillar) of cardiac and skeletal muscle. The roles of adrenergic stimulation, the renin-angiotensin system, and cytokines are evaluated as factors responsible for the systemic energy deficit. We propose a cylic AMP-mediated mechanism by which increased adrenergic stimulation contributes to the mitochondrial dysfunction.
\end{abstract}

\section{Keywords}

heart failure; mitochondria; heart; skeletal muscle; oxidative phsophorylation

\section{Introduction}

Heart failure (HF) is a complex clinical syndrome characterized by impaired contractile performance of the myocardium leading to inability of the heart to supply adequate amounts of blood to meet the metabolic needs of peripheral tissues. Increased preload and afterload, neurohormonal dysregulation, cardiac ischemia, and intrinsic abnormalities of the myocardium are common etiologic factors of HF. The progression of HF is dictated by changes in major signal transduction pathways, abnormalities of calcium homeostasis and energy fluxes, and alterations of the cardiac contractile apparatus. The impairment of bioenergetics is considered key in the progression of HF. The ATP that the myocardium has to synthesize and transfer to sustain the excitation-contraction coupling must continuously support an optimal myocardial performance in both systolic and diastolic periods. The heart

\footnotetext{
Address for correspondence: Charles L. Hoppel, M.D., Case Western Reserve University, School of Medicine, Department of Pharmacology, 10900 Euclid Avenue, Cleveland, OH 44106-4981, Tel: 216368 3147, Fax: 216368 5162, charles.hoppel@ case.edu. Document stating conflict of interest.

Drs. Mariana G. Rosca and Charles L. Hoppel do not have any conflict of interest to declare in regards to the work presented in this manuscript.
}

DISCLOSURE

The authors have nothing to disclose. 
has no excess capacity for energy production over energy utilization since during maximal exercise cardiac muscle uses $90 \%$ of its oxidative capacity. Ninety percent of this requirement is met by mitochondrial oxidative phosphorylation, which is finely tuned to energy need on a "pay as you go" basis. Cardiac energy deficits have been reported in HF that are due to impairment of all components of cardiac bioenergetics [1]. Moreover, the fetal gene expression pattern with downregulation of major metabolic and mitochondrial oxidative pathways is correlated with hemodynamic markers of severity in human HF [2].

Although exercise intolerance and early fatigue are important components of the HF syndrome, the decrease in maximal exercise capacity is more severe than predicted by indexes of left ventricular dysfunction. This has led to the conclusion that skeletal muscle myopathy, although triggered by alterations in central hemodynamics, becomes an independent phenomenon in HF. High-energy phosphate stores are lower in skeletal muscle in patients with HF [3] even after cardiac transplantation [4], supporting the concept that skeletal muscle also experiences compromised bioenergetics in HF. Therefore, generalized bioenergetic failure may represent the unifying mechanism that would explain the occurrence of both cardiac and skeletal muscle pathology in HF.

Similar to myocardium, postural muscles are highly oxidative and must continuously adjust energy production to utilization. In contrast, locomotion skeletal muscles have a greater plasticity in response to changes in functional requirements due to both the fiber typespecific expression of large-isoform families of muscle proteins and the specific energy metabolism that supports the velocity of contraction. For example, locomotion muscles have large energy stores in the form of creatine phosphate as well as high creatine kinase activity that can phosphorylate ADP to ATP and cope with myosin ATPase activity. In contrast to the myocardium, this type of muscle can afford drops in energy reserves that are replenished by glycolysis and mitochondrial oxidative phosphorylation.

This review focuses on the accumulated evidence in human subjects and animal models regarding the decrease in mitochondrial energy production as a key player in the progression of HF. We evaluate alterations in mitochondrial morphology and biogenesis, and substrate oxidation coupled with ATP synthesis in the context of their contribution to the chronic systemic energy deficit. Adrenergic stimulation, the renin-angiotensin system, and inflammatory cytokines are possible factors responsible for the systemic bioenergetic failure.

\section{Cardiac and skeletal muscle mitochondrial populations in health and disease Morphology}

Conventional transmission electron microscopy of mammalian cardiac and skeletal muscle tissues reveal mitochondria as individual organelles situated either in clusters beneath the sarcolemma (subsarcolemmal mitochondria, SSM) or in longitudinal rows within the contractile apparatus (interfibrillar mitochondria, IFM)[5]. The two mitochondrial populations differ in the heart in cristae morphology, with a lamelliform structure in SSM, whereas there is a tubular structure in IFM [6]. Lukyanenko et al. describe the perinuclear mitochondria as small circular entities in cardiomyocytes [7]. Intranuclear mitochondria were reported in human subjects with hypertrophic $[8,9]$ and alcoholic cardiomyopathy, and in rodents with alcoholic cardiomyopathy [10]; it is speculated that these mitochondria would facilitate the delivery of proapoptotic factors to the nucleus as the final destination [10], but the mechanism has not been identified. While the intra- and perinuclear mitochondria were observed as different microscopic subpopulations, their biochemical properties were not described. 
Dabkowski et al. showed that in mice isolated cardiac SSM are larger and have greater internal complexity compared to the smaller and more compact IFM [11]. Using highresolution scanning electron microscopy we found that, in contrast to SSM, rat cardiac IFM are structurally plastic, changing during the isolation procedure [12]. In rat ventricle myocytes using immunofluorescent labeling of the voltage dependent anion channel as a mitochondrial marker IFM are larger and more pleomorphic than perinuclear mitochondria [7]. In both cardiac and skeletal muscle, the special organization of IFM favors their interaction with the sarcoplasmic reticulum, thus offering a support for the $\mathrm{Ca}^{2+}$-mediated interaction between the two organelles. For example, IFM span the sarcomere from one Zdisk to another and are surrounded by the sarcoplasmic reticulum network. This position suggests that local $\mathrm{Ca} 2+$ concentration signals and influences mitochondrial function, and reciprocally, mitochondria may contribute to the local control of $\mathrm{Ca} 2+$ signaling. Slowoxidative muscles, such as cardiac and type 1 skeletal muscle, contain functional units, termed intracellular energetic units [13], in which ATP and ADP are focally released and directly transferred by channeling between mitochondria (the site of energy production) and sarcoplasmic reticulum and myofilament ATPases (sites of energy utilization). During HF, cardiac IFM are reported to lose their functional connection with the sarcoplasmic reticulum [14].

The morphology of these groups of mitochondria is dynamic and responsive to challenges in both cardiac and skeletal myocytes. For example, both endurance exercise- and aortic constriction-induced cardiac adaptive hypertrophy are accompanied by increased size of mitochondria [15]. By examining endocardial biopsies from humans with hypertrophic and dilated cardiomyopathy, Baandrup et al. found giant mitochondria with decreased matrix density and increased mitochondrial number [16]. Also, in a canine model of chronic HF of moderate severity, an increased number of smaller mitochondria with loss of matrix density and intramitochondrial myelin figures were found [17].

Exercise training leads to major adaptations in skeletal muscle, including an increase in capillary supply correlated with increased mitochondrial volume. In contrast, HF is associated with an overall disarray in mitochondrial structure [18] and decrease in cristae surface [19] suggesting a drop in oxidative capacity of the working muscles.

\section{Mitochondrial biogenesis}

Mitochondrial division is controlled by transcription of both mitochondrial and nuclear DNA, requires synthesis of new phospholipids and proteins, and is dependent on the fission process. By increasing the transcriptional activity of the nuclear respiratory factors (NFRs) on mtTFA promoter and of PPARa, the peroxisome-proliferator-activated-receptor (PPAR) gamma co-activator (PGC-1a) is the master synchronizer of the two genomes. Nuclear respiratory factors increase the expression of mtTFA as well as the vast majority of nuclearencoded subunits of the tricarboxylic acid cycle and ETC complexes. Mitochondrial transcription is initiated by the binding of the mitochondrial transcription factor A (mtTFA) on an upstream enhancer of the two mitochondrial DNA strands. PGC-1a controls optimal mitochondrial content, and its amount is directly correlated with mitochondrial density in both cardiac and skeletal muscle [20,21]. Also, in healthy subjects, the expression level of PGC-1a, its downstream transcription factors, and mitochondrial proteins are linearly related with maximal oxygen uptake, indicating that energy generation is a key factor in determining maximal effort capacity [22].

Mitochondrial biogenesis in physiological hypertrophy-Endurance exercise training improves cardiovascular and muscle function; an important component of the beneficial effect of training is the improvement in energy homeostasis. The adaptive 
responses of the heart to exercise training are physiological hypertrophy, bradycardia, and an increase in end-diastolic dimension. Studies on changes in energy production and transfer upon exercise training have reported conflicting results, with some showing that exercise favors an increase in myocardial mass rather than mitochondrial content. Notably, fatty acid oxidation is reported to be unchanged, suggesting the absence of metabolic remodeling in physiological hypertrophy.

It has been known for more than 40 years that chronic exercise causes an increased mitochondrial content in all skeletal muscle fiber types, thereby improving muscle capacity for ATP production. For example, physical activity complemented with weight loss is associated with an increased number and volume of skeletal IFM in obese human subjects [23]. Skeletal SSM seem to be more responsive to proliferation in disease states, as shown by the decrease in density in type 2 diabetes [24], and an increase in density in mice overexpressing PPARa.

Mitochondrial biogenesis in pathological hypertrophy and HF-The activities of the mitochondrial marker enzymes citrate synthase and cytochrome c oxidase, as well as the expression of oxidative phosphorylation genes, are unchanged when measured in the homogenates of cardiac tissue originating from pressure overload-hypertrophied hearts [25, 26]. These data suggest that mitochondrial density matches the energy demand of the hypertrophic cardiomyocyte during compensated cardiac hypertrophy.

The relationship between mitochondrial proliferation and pathologic cardiac muscle hypertrophy is highlighted by the discovery that polymorphisms in the PGC1a gene are correlated with an increased risk for hypertrophic cardiomyopathy [27]. Dai et al. recently showed that the cardiac hypertrophic effect of angiotensin II in mice is mediated by mitochondrial ROS and associated with increased mtDNA deletions and decreased copy number [28]. In these experiments, the upregulation of mitochondrial biogenesis signaling induced by both angiotensin II and experimental mtDNA deletions is completely blunted when the disease progresses to HF. Ventricular pressure overload studies in mice and studies with cultured cardiomyocytes, show that during the progression of hypertrophic growth cardiac PPARa gene expression falls and its activity is altered at the posttranscriptional level via the extracellular signal-regulated kinase mitogen-activated protein kinase pathway. Hypertrophied myocytes exhibit impaired cellular lipid homeostasis, suggesting metabolic remodeling [29].

Garnier et al. found that HF induced by aortic banding in rats is associated with downregulation of all main transcription factors of mitochondrial biogenesis [30]. In this study, the amount of PGC1a mRNA is linear with the expression of both the mitochondrial marker enzyme, citrate synthase, and two protein subunits of cytochrome $c$ oxidase encoded by mitochondrial and nuclear DNA. Because the mtDNA content is not affected, the authors conclude that in HF PGC1a controls mitochondrial transcription whereas mitochondrial DNA replication is independent of PGC1a. In skeletal muscle the authors report a similar depression in mitochondrial transcription factors suggesting a common mechanism for both cardiac and skeletal muscle bioenergetic deficit in HF in animals.

In animal models, the general conclusion is that PGC1a is upregulated during compensated hypertrophy and downregulated in HF. In the progression from compensated hypertrophy to $\mathrm{HF}$, there is generalized adrenergic, renin-angiotensin, and cytokine stimulation; many of these have been shown to stimulate rather than inhibit PGC1a expression. Also, signaling pathways that are upregulated in HF, such as AMPK, MAPK and calcineurin signaling, activate the PGC1a pathways [31,32]. Therefore, the molecular mechanism for the drop in PGC1a signaling upon the transition from compensated hypertrophy to HF is unidentified. 
Information about mitochondrial biogenesis in human HF is in conflict. The amount of mtTFA, mtDNA, and mRNA for all mitochondrial-encoded subunits of the ETC is normal in explanted failing heart when compared with donor hearts, excluding a generalized decline in mitochondrial gene expression [33]. No evidence for altered mitochondrial biogenesis is found in skeletal muscle of HF human subjects as well [34]. However, in both studies, retrospective analysis of drug therapy before transplantation identified beta-blockers as providing putative protection against this disturbance. Toth et al. recently reported that clinically-stable human subjects with moderately severe HF (New York Heart Association function class II) experience minimal changes in mitochondrial density, transcriptional regulators, gene expression, and activity of mitochondrial marker enzymes in skeletal muscle [35] when the effect of muscle disuse is eliminated. In contrast to less severe HF, the evaluation of a large cohort of human subjects revealed that decreased mitochondrial density emerges late in the course of the disease (NIHA function class IV), is correlated with the maximal oxygen uptake irrespective of age and etiology of $\mathrm{HF}$, and resembles the deconditioning effect of prolonged immobilization [36].

In right ventricular failure induced by chronic obstructive pulmonary disease (COPD), the oxidative properties vary in the diaphragm and limb muscle (quadriceps) in opposite directions. The increased work of breathing in COPD is considered responsible for the increased mitochondrial density and respiratory properties in the diaphragm that are correlated with the index of obstruction [37]. In contrast, decreased mitochondrial density is reported in vastus lateralis in patients with COPD [38], whereas the mitochondrial respiratory function is preserved [39].

In contrast to acquired HF, primary mitochondrial cardiomyopathy in human subjects leads to mitochondrial proliferation in the heart [40]. Mitochondrial proliferation also is found in murine models of cardiomyopathies associated with ablation of either the adenine nucleotide translocase 1 [41], frataxin [42], Mn-SOD [43], or mtTFA [44]. The ANT1-deficient mouse also experiences exercise intolerance despite the dramatic mitochondrial proliferation in skeletal muscle [41]. Notably, the increased mitochondrial mass in the myocardium of mtTFA knockout mice is accompanied by a decrease in mtDNA replication and transcription, as well as impaired mitochondrial electron transport chain (ETC) [44]. The increased mitochondrial number cannot compensate for the mitochondrial defect as shown by severe ATP depletion.

Taken together, these observations suggest that there is a reciprocal relationship between alterations in mitochondrial biogenesis and both cardiac and skeletal pathology. What are the mechanisms leading to changes in mitochondrial biogenesis in pathological cardiac hypertrophy and failure?

Oxidative stress is considered an important candidate responsible for cardiac remodeling in response to stress. Reactive oxygen species (ROS)-induced signaling is involved in cardiac remodeling by controlling the coordinate increase in cardiomyocyte volume, mitochondrial biogenesis and capillary density. For example, oxidative stress induced by hypertrophic stimuli leads to oxidation of the conserved cysteine residues in class II histone deacetylases, the master negative regulators of cardiac hypertrophy; this event results in their export to the cytosol where they can no longer inhibit specific transcription factors, such as the nuclear factor of activated $\mathrm{T}$ cells and myocyte enhancer factor 2 resulting in cardiac hypertrophy [45]. Similarly, the expression of both PGC1a and $1 \beta$, as well as their promoter activity, is increased by ROS and leads to increased expression of mitochondrial electron transport genes, and mitochondrial and cytosolic ROS-detoxifying systems via a cAMP response element-dependent mechanism [46], suggesting that moderate oxidative stress is an important candidate contributing to increased mitochondrial biogenesis in cardiac 
hypertrophy. Additionally, ROS generated by cardiomyocyte NADPH oxidase-4 (NOX4) increases myocardial angiogenesis in pressure overload stress [47].

The latter observation leads to the hypothesis that ROS originating from distinct spatiallyrestricted cellular sources regulate different signaling pathways and are either beneficial or detrimental to cardiomyocytes. For example, ROS may be produced within cardiomyocytes by several sources including mitochondria, $\mathrm{NAD}(\mathrm{P}) \mathrm{H}$ oxidase, xanthine oxidase and uncoupled nitric oxide synthase. Mitochondria produce superoxide through a single electron reduction of molecular oxygen when electrons leak from high-electron pressure sites within the electron transport chain (ETC) as a result of defects in ETC complexes [48-53]. Myocardial NADPH oxidase activity is increased in the failing human heart [54], and both expression and activity of the mitochondrial NADPH oxidase- 4 are increased in rodent hearts in response to pressure overload [55]. Endogenous NOX4, partially localized within the mitochondria, is reported to mediate mitochondrial dysfunction and decrease in mtDNA content in the heart during pressure overload-induced pathological hypertrophy potentially via inducing oxidative damage of mitochondrial respiratory complexes and mtDNA content [55]. In sharp contrast to this finding, the cardiomyocyte NOX4 with a perinuclear endoplasmic reticulum distribution protects against pressure overload stress by increasing myocardial angiogenesis [47]. These data suggest that ROS generated within cardiomyocytes are essential members of an adaptive and coordinated signaling pathway when the heart faces overload stress. However, extensive ROS production leads to decreased mitochondrial bioenergetics that impedes the heart in adapting to chronic stress, and leads to HF.

\section{Biochemical properties of cardiac and skeletal SSM and IFM}

Cardiac SSM and IFM differ both in their inherited properties and in response to disease. Rat [56], rabbit [57], hamster [58], and human [59] heart IFM oxidize substrates at higher rates compared with heart SSM, with no differences in their coupling abilities and cytochrome content. SSM are more susceptible to calcium overload-mediated cytochrome $c$ release and mitochondrial damage compared with IFM [60].

An increased susceptibility of cardiac SSM to ischemic damage has been observed in rat [61] and rabbit [62]. SSM also produce reactive oxygen species (ROS) following ischemic damage [63]. In contrast, the age-related decrease in both the amount of IFM and oxidative phosphorylation [57] is associated with increased susceptibility towards mitochondrial permeability transition pore opening [64]. The age-related mitochondrial defects in cytochrome $b$ in complex III predispose to a greater susceptibility to ischemia compared to adult hearts [65]. Despite an increase with age in the antioxidant defense mechanisms, a significant increase in oxidative stress markers was described in cardiac IFM compared with SSM [66]. Cardiac IFM also are more sensitive to diabetic damage [11] and act as triggers of apoptosis in the diabetic heart [67]. An equal decrease in the content of cardiolipin and activity of complex III occur acutely after myocardial infarction in both cardiac SSM and IFM, which leads to decreased mitochondrial respiration and increased ROS production [68]. A loss of cardiolipin also was reported in dilated cardiomyopathy in humans and in spontaneously hypertensive heart failure in rats, and was correlated with reduced complex IV activity in both populations of cardiac mitochondria [69]. In a model of microembolisminduced HF of moderate severity in dogs, we found that both populations of heart mitochondria experience a decrease in oxidative phosphorylation and amount of supercomplexes [70] without changes in cardiolipin content and molecular species [71].

Skeletal muscle also contains two subpopulations of mitochondria, SSM and IFM, which display differences in biochemical and functional properties. IFM show higher enzyme activities and respiratory rates [72] and import rates of precursor proteins, but lower levels 
of the phospholipid cardiolipin [73, 74]. It has not been established how these differences arise or if they are related to the higher adaptability of SSM to variations in the muscle. Closer proximity of skeletal SSM to nuclei and plasma membrane may explain the prompter proliferation response compared to IFM as a reply to challenges, such as exercise training, as well as their damage in diseases induced by altered signal transduction pathways [24], such as insulin resistance. Despite similar increases in antiapoptotic signals with exercise training [75], skeletal muscle IFM are more liable to initiate apoptotic signals in response to oxidative stress [76]. Because of their proximity to sarcoplasmic reticulum and their participation in the intracellular energy units, it is surmised that IFM mitochondria supply ATP to contracting myofibrils.

These data emphasize the importance of studying both mitochondrial populations when attempting to elucidate the contribution of mitochondrial dysfunction to cardiac and skeletal pathology.

\section{Cardiac and skeletal muscle mitochondrial dysfunction in HF}

It is proposed that myocardial bioenergetic failure worsens the clinical outcome of human subjects undergoing heart surgery for valvular defects, and that the investigation of mitochondrial function in myocardial biopsies is desirable in order to predict the postoperative cardiac mechanical complications [77]. To date, the approach to the investigation of mitochondrial function varies between laboratories. In the literature, the most common approach is to measure the activities of ETC complexes, marker enzymes, and ATP synthase in homogenates prepared from frozen-thawed tissue. A few studies use saponin-permeabilized fibers to measure mitochondrial oxidative phosphorylation.

Our approach has been to examine integrated mitochondrial function measured as oxidative phosphorylation in freshly-isolated intact SSM and IFM from cardiac and skeletal muscle. As a further step, we also measure the activities of ETC complexes and marker enzymes in both mitochondria and homogenates prepared from fresh cardiac and skeletal tissue. This approach provides not only a physiological and functional measurement to assess the impact of any ETC complex defect on oxidative phosphorylation, but also a database to perform recovery studies by comparing the mitochondrial yield obtained after isolation with the mitochondrial content in the original tissue. Also, similar results in tissue homogenates and isolated mitochondria rule out the occurrence of tissue extramitochondrial factors that affect mitochondrial ETC complex activity and that are lost during isolation procedure.

\section{Abnormalities in the integrated mitochondrial function and respirasomes}

By investigating mitochondrial function over the course of the disease, it is concluded that compensatory cardiac hypertrophy is associated with an increase in cardiac mitochondrial oxidative capacity, and that in congestive HF mitochondria exhibit pronounced dysfunction. For example, Doenst et al. report that the pattern of substrate oxidation predicts the progression of HF in rats with aortic arch constriction [78]. The oxidation of the complex I substrate, glutamate, has a biphasic pattern with an early increase followed by a decline that coincides with the drop in contractility and ejection fraction. Decreased mitochondrial fatty acid oxidation precedes the decline in contractility. Upon the addition of an uncoupler, oxygen consumption similarly increases in catecholamine-perfused normal and pressureoverload hypertrophied swine hearts but not in failing hearts, indicating that mitochondrial oxidative capacity (proximal to the phosphorylation apparatus) is preserved in compensatory hypertrophy and is decreased in HF [79]. A similar pattern is described in skeletal muscle; Schrepper et al reports a biphasic response of skeletal muscle mitochondria to chronic cardiac pressure overload [80], with an early increase in mitochondrial oxidative 
phosphorylation and a later decline that coincides with the transition from cardiac hypertrophy to chronic HF.

Decreased state 3 respiratory rates (ADP-dependent) were found when oxygen consumption was measured in the presence of glutamate+malate in saponin-permeabilized cardiac fibers isolated from rat [30,81], dog [17], and human [82] hearts with dilated cardiomyopathy as well as in pressure overload- and ischemic-induced HF [82, 83]. Similarly, the failing human heart experiences early defects in complex I-linked respiration and fatty acid oxidation, as well as in the phosphorylation apparatus [84]. In their studies, both Sharov et al. [17] and Lemieux et al. [84] ruled out the decrease in mitochondrial density as a cause for the decrease in respiratory rates in HF [17], and concluded that the decrease of the respiratory rates measured in cardiac fibers is due to decreased mitochondrial function.

Respiratory studies using cardiac fibers do not differentiate between the two distinct mitochondrial populations, SSM and IFM [5, 56] which may be differentially affected by HF. Lindenmayer et al. used polytron treatment to isolate heart mitochondria (isolating in fact the SSM only), and reported a decrease in glutamate- and succinate-supported state 3 respiratory rates in heart SSM isolated from guinea pigs with congestive HF induced by stenosis of the ascending aorta [85]. A similar model of HF in rabbits was associated only with $22 \%$ decrease in glutamate+malate- and succinate- supported state 3 respiratory rates of heart mitochondria [86]. The experimental protocol (protease, nagarse, complemented by polytron homogenization) indicates that the latter authors isolated both heart SSM and IFM as a single admixed fraction. The milder decrease in state 3 respiratory rates compared with that in the Lindenmayer study is explained by the use of a mix of the two types of heart mitochondria - Lindenmayer used only SSM - and points to the fact that the two mitochondrial populations are differently affected by HF. This circumstance would partially mitigate the severity of the observed defect. The control of oxygen consumption by phosphorylation ("coupling") is lost in pressure overload congestive HF as indicated by the decreased respiratory control ratio (state 3 rate (ADP-stimulated)/state 4 rate (ADP-limited) $[85,86]$ with little or no changes in the efficiency of oxidative phosphorylation, as shown by normal ADP/O ratio [85, 86].

Our approach to the integrated function of the ETC coupled to ATP synthesis, membrane transport, dehydrogenase activities, and the structural integrity of the mitochondria is the analysis of oxidative phosphorylation in freshly-isolated cardiac SSM and IFM. By investigating the two metabolically and structurally distinct populations of mitochondria [58] we were able to reconcile the disparate finding regarding the oxidative properties of heart mitochondria in dystrophic cardiomyopathy in hamsters [87, 88]. A decrease in respiratory state 3 rates with complex I or II substrates was present only in IFM. The activity of ETC complexes and the amount of cytochromes were normal. The decrease in state 3 respiratory rates was reversed by the addition of an uncoupler, indicating that the defect lay in the phosphorylation apparatus. The control of oxygen consumption by phosphorylation ("coupling") as well as the efficiency of oxidative phosphorylation was preserved. The defect in IFM was progressive and paralleled the degree of peripheral congestion [58].

In a follow-up to the work performed by Sharov et al. on oxidative phosphorylation in saponin-permeabilized cardiac fibers in canine intracoronary microembolization-induced HF of moderate severity [17], we performed a study of respiratory properties of the two populations of freshly-isolated heart [89] and skeletal muscle mitochondria. Both populations of heart mitochondria were equally affected in this model of HF with a dramatic decrease in respiratory rates with substrates donating electrons at complex I, II, III, and IV caused by a decreased amount of the $\mathrm{I} / \mathrm{III}_{2} / \mathrm{IV}$ respirasome [89]. In contrast to heart muscle, skeletal muscle mitochondria have the defect localized in IFM, whereas the function of SSM 
is preserved. Oxidative phosphorylation rates of skeletal IFM are decreased through complex I associated with a decreased amount of the $\mathrm{I} / \mathrm{III}_{2}$ supercomplex (unpublished observation). The functional significance of the $\mathrm{I} / \mathrm{III}_{2}$ supercomplex for the decrease in complex I-supported oxidative phosphorylation in skeletal muscle IFM is unknown. The occurrence at an early stage of the disease of mitochondrial dysfunction and decreased supercomplex organization also leads to the hypothesis that the decline in bioenergetics contributes to the progression of HF.

Rapid ventricular pacing in dogs-an experimental model of HF that mimics the human idiopathic dilated cardiomyopathy—causes increase in chamber dimensions, mural thinning, elevation in ventricular stress, and congestive HF. We performed a comprehensive examination of oxidative phosphorylation of the two populations of cardiac mitochondria isolated from cardiac septum and left ventricular wall, as well as skeletal mitochondria from gastrocnemius. Oxidative phosphorylation is decreased at complex III in both SSM and IFM isolated from the cardiac septum. In the left ventricle lateral wall, only IFM are the target of damage with decreased oxidative phosphorylation at complexes I, II, and III that is partially relieved by the uncoupler, dinitrophenol, with complex II and III substrates. These data suggest a complex alteration of cardiac mitochondria in this type of HF involving the components of the phorphorylation apparatus and possibly the organization in supercomplexes (unpublished observation). The data also indicate a regional distribution of mitochondrial defects with the cardiac septum being the major target.

Oxidative phosphorylation at complexes I, II, and III of both populations of gastrocnemius mitochondria also is decreased in pacing-induced HF [72]. Lack of relief of respiratory rates in skeletal muscle SSM in the presence of the uncoupler shows a defect in the ETC which needs further investigation. We further found a decrease ATPase activity and ANT2 amount in SSM, but these defects do not seem to have an effect on oxidative phosphorylation. In contrast, the decrease in the ADP-stimulated respiration in skeletal muscle IFM was relieved by the uncoupler, dinitrophenol, pointing to a defect in the phosphorylation apparatus rather than in the ETC. Respiratory rates are partially improved in IFM when ADP at saturating concentrations are used, indicating a decrease in the nucleotide transport capacity of the ANT. We found an alteration in the ANT isoform protein profile in skeletal IFM isolated from HF characterized by an increase in the amount of ANT1 and a decrease in the amount of ANT2. Because the respiratory rates in both SSM and IFM are positively correlated with the amount of ANT2, the high-capacity transport isoform, we conclude that this shift in ANT isoforms may explain this functional trait [72].

We conclude that studies on mitochondrial function in freshly-isolated cardiac and skeletal SSM and IFM give an accurate picture of the consequence of the ETC complex defects in HF. Also, the assessment of integrated mitochondrial function as oxidative phosphorylation is the only assay able to localize the defect within the oxidation side or phosphorylation apparatus, and should direct further investigation towards indentifying the specific defect.

\section{Defects in individual components of the ETC and phosphorylation apparatus in HF}

Variable mitochondrial defects have been reported in the ETC complexes and components of the phosphorylation apparatus in heart mitochondria in HF of different etiologies, and was briefly evaluated by us in recent reviews $[90,91]$.

Most laboratories perform the measurement of ETC complex activities on homogenates or mitochondrial particles prepared from frozen-thawed cardiac and skeletal muscle tissue. Using the pacing-induced model in dogs as a model of human dilated cardiomyopathy, Marin-Garcia et al. reported a severe decrease in the activity of complex III in frozenthawed cardiac tissue homogenates [51-53]. A decrease in complex III activity also is found 
in frozen-thawed cardiac tissue homogenates from human subjects with either idiopathic or ischemic dilated cardiomyopathy undergoing cardiac transplantation [50]. Based on mitochondrial particles isolated from frozen cardiac tissues, Ide et al. reported a decrease in complex I activity in pacing-induced canine HF [49], whereas in human dilated cardiomyopathy Buchwald et al. found defects in complexes III and IV in human dilated cardiomyopathy [48]. A complex IV defect also is reported in an experimental model of pressure overload HF, the spontaneous arterial hypertension in rats, when measured in frozen-thawed isolated cardiac mitochondria [69].

Alterations in the components of the phosphorylation apparatus characterized by decreased amount and activity of ATP synthase were reported in pig cardiac tissue with ischemic HF induced by left circumflex coronary artery ligation [92], as well as in dogs with dilated cardiomyopathy [93] and human patients with dilated cardiomyopathy [94]. Complex V activity is severely decreased when measured in both cardiac and skeletal muscle frozenthawed homogenates from dogs with pacing-induced HF [51-53]. Based on the observation that adenine nucleotide translocase (ANT) antibodies are present in the plasma of patients with dilated cardiomyopathy and the fact that they inhibit the nucleotide transport of cardiac mitochondria [95], Schultheiss et al. found a decrease in the ANT transport capacity in explanted cardiac tissue of patients with dilated cardiomyopathy [96] associated with an increase in the amount of the total ANT protein [97]. The analysis of human heart tissues reveals a shift in the ANT isoform expression characterized by an increase of the ANT1 and a decrease in ANT2 [98], which restricts ANT function [99]. Altered ANT isoform expression also was found in endomyocardial biopsies during earlier stages of dilated cardiomyopathy, suggesting that the ANT defect may cause the energy deficit and progression of HF. The ANT shift also occurs in inflammatory cardiac diseases, but is absent in ischemic, valvular and hypertrophic cardiomyopathy [98].

In conclusion, measurements performed in frozen-thawed cardiac tissue homogenates show that HF of different etiologies is associated with a broad variety of mitochondrial defects that may contribute to energy deficit and to the progression of the disease. We believe that these variations in the results may be explained at least in part by technical differences in tissue processing. Key factors having significant influence on the spectrophotometric assays of activities of individual ETC complexes include whether the activity is measured in frozen-thawed or fresh samples and the method of mitochondrial disruption. ETC individual complex activities require the integrity of protein subunits, their assembly in active complexes, and the lipid microenvironment of the inner membrane enriched in cardiolipin [100-110]. ETC complex activities are measured spectrophotometrically as specific donoracceptor oxidoreductase activities with both donor and acceptors spanning specific regions of the ETC. Because both freezing-thawing procedure for preservation and detergenttreatment for solubilization alter the mitochondrial inner membrane cardiolipin, a source of cardiolipin-exogenous soybean asolectin -is needed in order to obtain the optimal enzyme activities. Also, the decrease of ETC activities measured in tissue homogenates may be attributed to either a decrease in mitochondrial density or mitochondrial ETC defects. Therefore, in order to identify the specific cause of the decrease in tissue oxidative capacity, the ETC activities must be accompanied by the measurement of mitochondrial marker enzymes.

In order to avoid this variability, Quigley et al. measured ETC activities in human subjects with HF using freshly-isolated cardiac mitochondria and frozen-thawed homogenates prepared from samples of the left ventricles at cardiac transplantation [111]. These authors report a decrease in complex IV activity in freshly-isolated heart mitochondria that correlates with the decrease in the ejection fraction of the affected heart. Their data suggest that the use of frozen tissue homogenate does not accurately gauge mitochondrial damage. 
At a moderately severe stage of canine microembolism-induced HF we found that the individual mitochondrial ETC complexes are unchanged by measuring their individual activities in both freshly-prepared cardiac homogenates and mitochondrial populations. The defect resides in their assembly in respirasomes that support oxidative phosphorylation [70]. Similar to the heart, individual ETC complexes in skeletal muscle are unchanged; instead, their organization in supercomplexes appeared to be altered. In addition, the mitochondrial marker enzyme, citrate synthase, the NADH-cytochrome $\mathrm{c}$ and succinate-cytochrome $\mathrm{c}$ linked activities, as well as the calculated mitochondrial content are increased, indicating skeletal mitochondrial proliferation (unpublished observation).

In the canine pacing-induced HF model, we found a decrease in complex I-III activity expressed as rotenone-sensitive NADH cytochrome $\mathrm{c}$ reductase when using tissue homogenate prepared from both septum and lateral wall of the left ventricle, not reflected by a similar defect in corresponding SSM and IFM (unpublished observations), suggesting an extramitochondrial inhibitor factor that is lost during the isolation procedure. These data highlight the importance of measuring ETC complex activities in both tissue homogenates and isolated mitochondria. In contrast with the canine rapid paced-heart and in agreement with human dilated cardiomyopathy $[98,99,112]$, we found that the decrease in oxidative function of skeletal muscle mitochondria in dogs with pacing-induced HF is due to defects in the phosphorylation system, such as decreased oligomycin-sensitive activity of ATPase in SSM and an altered expression of the ANT isoforms in IFM [72].

Whether the purported mitochondrial ETC defects are causal factors or accompanying features in HF is still unclear [50]. Also, the assessment of activities of the individual ETC complexes cannot detect defects in integrated mitochondrial function where oxidation of substrates is coupled with electron transport and consumption of ADP to synthesize ATP. Therefore, the causal link between the reported ETC defects and the decrease in mitochondrial oxidative phosphorylation has not been defined in most of these studies. Why is this link important? The increase in oxidative capacity when the limitation by the phosphorylation system is released experimentally by an uncoupler [113] suggests that there is an apparent excess in ETC complex activity relative to the phosphorylation apparatus and the oxidative phosphorylation requirement $[114,115]$. The sites of control of respiration in normal heart isolated mitochondria are located at complex I in the ETC [116] and at adenine nucleotide translocase and complex $\mathrm{V}$ in the phosphorylation apparatus [117]. In human heart, the phosphorylation system was found to exert a strong limitation on oxidative phosphorylation [84]. In contrast, in intact cells the site of oxidative phosphorylation control is located in complex IV [118] due to the ATP-allosteric inhibition of the complex [119]. Therefore, the measurement of ETC complex activities must be complemented with the assay of oxidative phosphorylation in order to establish a causal link between the reported ETC defects and decreased mitochondrial function.

\section{Mechanisms responsible for the systemic mitochondrial myopathy in HF}

\section{Adrenergic stimulation}

HF is accompanied by adaptive reactions, including the release of norepinephrine and epinephrine from the cardiac adrenergic nerves, with secondary increase in heart rate and contractility. Although these adaptive mechanisms are adequate to maintain cardiac output at relatively normal levels during the initial development of HF, clinical data suggest that they ultimately become maladaptive and result in a progressive decrease in cardiac performance. $\beta 1$ receptors couple to the stimulatory $\mathrm{G}$ protein (Gs), activate adenylyl cyclase (AC), and increase cytosolic cAMP; the latter binds the regulatory subunits of protein kinase A (PKA) and releases the catalytic subunits (cPKA), which phosphorylates sarcolemmal L-type Ca channels and sarcoplasmic phospholamban, with increase in the 
cytosolic $\mathrm{Ca}^{2+}$ responsible for their positive chronotropic and inotropic effects. $\beta 1$ receptors also cause decreased expression of survival genes and increased pro-apoptotic signals that are involved in the transition from hypertrophy to decompensated HF. Instead, the dual coupling of $\beta 2$ receptors to both Gs and inhibitory $G$ proteins activates bifurcated signaling pathways via PKA and survival signals via phosphatidylinositol 3 kinase/Akt pathway [120]. Since the predominant cardiac $\beta$-receptor subtype is $\beta 1$ (85\% of cardiac adrenergic receptors [120]), these observations explain why the initial pronounced activation of the sympathetic system seen in animals and patients with HF is inversely correlated with survival. Clinically, the use of $\beta 1$-selective receptor blockers is beneficial [121, 122] causing a reduction in the risk of death by a third or more, a benefit greater than any other drug used in $\mathrm{HF}$.

A specific signal transduction pathway of $\beta 2$ adrenergic receptors occurs in mammalian cardiomyocytes. Phosphatidylinositol 3-kinase (PI3K)/protein kinase B (Akt) is the major survival signaling pathway for the $\beta 2$-adrenergic stimulation in the heart. Akt is a serine/ threonine kinase that is translocated in a membrane potential-dependent manner to the mitochondrial inner and outer membranes following the activation of PI3K in cells under stress conditions [123]. The $\beta$ subunit of ATP synthase was reported to be a mitochondrial substrate for Akt [123].

In mice, the exercise-induced increase in PGC1a in skeletal muscle is partially due to the $\beta$ adrenergic receptor activation [124], suggesting a role of the increased sympathetic tone in increased mitochondrial biogenesis. In contrast, acute excessive $\beta$-adrenergic stimulation in humans does not increase mitochondrial protein synthesis or markers of mitochondrial biogenesis in skeletal muscle [125]. Also the administration of the $\beta 2$ agonist, clenbuterol, to human subjects induces skeletal and cardiac hypertrophy due to increased protein synthesis and decreased protein degradation [126], and decreases mitochondrial content and function measured as fatty acid and pyruvate oxidation by altering PGC1a signaling [127]. These observations suggest a potential contribution of adrenergic stimulation to the skeletal muscle energy deficit in HF.

\section{Potential mechanism by which increased adrenergic drive induces bioenergetic failure in HF-The $\beta 1$-adrenergic-cAMP signaling is limited by cAMP} diffusion, the local imbalance between cAMP formation (adenylyl cyclase) and destruction (phosphodiesterases), the dual activation of $\beta 1$ and $\beta 2$ receptors with different signaling pathways, and restriction imposed by the presence of PKA. The net content of cAMP in the cytosol seems to have low significance. Mitochondria are unique organelles, in part due to the controlled import of anions through the outer membrane via the voltage dependent anion channel (VDAC) that may lead to an increase of cAMP in the mitochondrial intermembrane space compartment. High concentrations of cAMP were reported in mitochondria [128] that increase $2-3$ seconds after activation of $\beta$-adrenergic receptors with the $\beta$-agonist, isoproterenol [129], suggesting that mitochondrial cAMP/PKA signaling is rapidly activated by the adrenergic drive. Several observations provide the basis for a specific mitochondrial cAMP-PKA signalling pathway: 1) PKA is present in mitochondria [128, 130-133]; 2) soluble adenylyl cyclase is present in mitochondria, is regulated by intramitochondrial bicarbonate and calcium, and exerts short-term regulation of cytochrome c oxidase via phosphorylation of its protein subunits [134]; because soluble adenylyl cyclase is not connected with the AR-linked membrane adenylyl cyclase pathway, this intramitochondrial pathway may represent a local mechanism by which ETC flux is adjusted with the tricarboxylic acid cycle; 3) more than 60 mitochondrial proteins are phosphoproteins [130] with half phosphorylated at serine/threonine residues. Protein subunits of all mitochondrial ETC complexes are reported to be potential targets of cAMP-dependent phosphorylation [91]. A therapeutic benefit of $\beta 1$-blockers is protection against oxidative stress [135-137]. 
The impairment of the supermolecular organization of ETC complexes in supracomplexes seems to be an early event during the progression of HF in both heart and skeletal muscle. In later stages, Schrepper et al. report that the skeletal mitochondrial dysfunction is due to decrease in individual activities of ETC complexes rather than alterations in supercomplexes [80].

In a follow-up to our finding that decreased mitochondrial function is due to decreased amount of the I/III2/IV respirasome in the moderately-severe microembolism-induced HF, we asked whether this defect in the supramolecular assembly is due to changes in the phospholipids of the mitochondrial inner membrane or modifications of the subunits of the ETC complexes. The content of the main phospholipid species, including cardiolipin, as well as the molecular species of cardiolipin, were unchanged in cardiac mitochondria in HF [71]. In heart mitochondria isolated from HF, complex IV not incorporated into the respirasomes exhibited an increased content of threonine phosphorylation, suggesting that cAMP-dependent phosphorylation may have a role in this process. In saponin-permeabilized heart muscle fibers, cAMP caused a decrease in oxidative phosphorylation, at least at the level of complex IV. We suggest that cAMP-dependent phosphorylation of specific complex IV subunits either limits the incorporation of complex IV into supercomplexes or decreases supercomplex stability.

In this regard, we propose a sequential mechanistic pathway in which the increase in adrenergic drive causes a decrease in functional respirasomes as a primary event leading to mitochondrial dysfunction and progressive decrease in cardiac performance. The cAMP generated by $\beta$-adrenergic receptor-linked adenylyl cyclase is transported into the mitochondrial intermembrane space (IMS) through the mitochondrial outer membrane voltage-dependent anion channel. cAMP binds to the regulatory subunits of the cAMP dependent kinase (PKA) exposed on the IMS side of the mitochondrial inner membrane, causing the release of the catalytic subunits, which phosphorylate serine and threonine residues on the matrix-exposed subunits of cytochrome $c$ oxidase. These postranslational modifications impair the incorporation of cytochrome $c$ oxidase into supercomplexes, reduce the amount of functional respirasomes, and decrease mitochondrial oxidative phosphorylation. These modifications result in decreased ATP generation and the accompanying energy deficit. Improper organization of ETC complexes in supramolecular assemblies also impedes electron channeling in the ETC with an increase in electron leak and superoxide generation from complexes I and III, which are not incorporated within respirasomes. Complex I and III-generated superoxide is dismutated by the matrix and intermembrane space superoxide dismutases, respectively, to diffusible hydrogen peroxide, which damages adjacent mitochondrial inner membrane proteins including subunits of the ETC complexes and cytosolic myofibrillar proteins. These oxidative alterations, which cause the decreased activity of ETC complexes reported by others in severe HF, potentially augment the severity of the energy deficit and oxidative stress, and finally lead to the degradation of the oxidized complexes. Oxidative damage to myofibrillar proteins decreases calcium sensitivity, thus interfering with muscle contractile performance. In support of our hypothesis, sarcomeric proteins are preferentially oxidized in in vitro models [138, 139]. The increased oxidation and degradation of myosin heavy chain in the diaphragm and soleus muscle are reversible upon treatment with the $\beta$-blocker agent, carvedilol [140], highlighting the role of adrenergic stimulation in the systemic myopathy in HF.

\section{Renin angiotensin aldosterone system}

The renin-angiotensin-aldosterone pathway seems to have divergent effects on cardiac and skeletal muscle. Angiotensin II infusion causes cardiac hypertrophy via increased ROS generation and DNA damage [28]. Although NADPH oxidase activity and content are 
reported $[141,142]$ to be increased upon angiotensin infusion, mitochondrial-generated ROS have the decisive role in this response because the overexpression of mitochondrial catalase relieves the degree of cardiac hypertrophy [28]. However, angiotensin II-induced ROS is decreased by the NADPH oxidase inhibitor, apocynin, indicating involvement of NADPH oxidase as a source of ROS [143]. Cross-talk between the main cardiac ROS generators, NADPH oxidase and mitochondria, is suggested, in which angiotensin II activates NADPH oxidase as the primary source of ROS causing mitochondrial dysfunction as an amplifier leading to increased oxidative stress [144]. The mitochondrial member of the NADPH oxidase family, NOX4, is upregulated by angiotensin II in a mitochondrial-ROS independent manner whereas NOX2 activation is mitochondrial ROS-dependent [28], suggesting an unknown but seemingly delicate relationship between the two sources.

In contrast, angiotensin II infusion has a hypercatabolic effect causing increased muscle protein degradation, apoptosis, and muscle atrophy [145]. It is unclear to what extent angiotensin receptors contribute to the direct effects of angiotensin II on skeletal muscle. Chronic treatment with angiotensin-converting-enzyme inhibitors or angiotensin II receptor blockers increase skeletal muscle peak oxygen consumption and apoptosis-induced atrophy in patients with HF, but does not relieve the decrease in skeletal mitochondrial complex I, II, and IV activities induced by cardiac ischemia-reperfusion [146], suggesting that the benefit of inhibiting angiotensin II in skeletal muscle is independent of the improvement of mitochondrial function. The effect of angiotensin II on muscle atrophy is related to stimulation of the suppressor of cytokine signaling (SOCS3) because this effect was suppressed in interleukin-6 deficient mice [145].

\section{Inflammatory cytokines}

Indicators of systemic inflammation are considered candidate biomarkers in HF [147]. On the one hand, interleukin 6 (IL6) is a strong prognostic marker for mortality in patients with HF [148]. On the other hand, IL6 prevents mitochondrial dysfunction in cardiomyocytes upon ischemia-reperfusion [149]. IL6 activates an important cardioprotector, the signal transducer and activator of transcription 3 (STAT3), which is located on mitochondria where it depresses the supply of electrons from complexes I and II to complex III and decreases ROS generation [150]. Therefore, the implication of IL6 in the progression of HF is unclear.

The proinflammatory cytokine, TNFa, has been linked to the left ventricle remodeling and progression to HF [151] as well as to mitochondrial dysfunction. Cardiac overexpression of TNFa causes HF that is associated with profound mitochondrial dysfunction [152]. TNFa increases the production of ROS [153], induces a mitochondrial complex III defect and DNA damage [154], and causes apoptosis in cultured cardiomyocytes [155]. The decrease in the activities of complex III and V in cardiac and skeletal muscle mitochondria of pacinginduced HF dogs is inversely correlated with plasma and cardiac TNFa levels [51]. In vivo $\mathrm{TNFa}$ inhibition with etanercept, a soluble p $75 \mathrm{TNF}$ receptor fusion protein, normalizes mitochondrial function and oxidative stress and decreases apoptosis in this experimental model of HF [53]. These observations suggest the involvement of systemic inflammation as a potential mechanism for the development of cardiac and skeletal mitochondrial dysfunction.

\section{Conclusions}

Heart failure is characterized by a decline in mitochondrial energy production in both cardiac and skeletal muscle, supporting the concept of a systemic mitochondrial cytopathy. Both mitochondrial biogenesis and function are affected, exhibiting a biphasic pattern with an early increase and a late decline that coincides with the transition from hypertrophy to heart failure. This pattern follows the expression of the master regulator of mitochondrial 
biogenesis, PGC1a. SSM and IFM react differently to HF of different etiology, with sites of defect varying with the etiology. The decrease in oxidative phosphorylation in cardiac and skeletal mitochondria from microembolism-induced HF is associated with decreased ETC supercomplexes. Pacing-induced HF is accompanied by complex mitochondrial defects localized within the ETC and the phosphorylation apparatus. These observations imply that different mechanisms related to the etiology of HF are responsible for systemic mitochondrial myopathy. Neurohormonal stimulation and inflammatory cytokines may contribute to the development of the systemic bioenergetic failure, and could provide an inviting target of choice for therapy.

\section{Acknowledgments}

We acknowledge Dr. Bernard Tandler (School of Dental Medicine, Case Western Reserve University) for editorial assistance.

\section{FUNDING SOURCES}

Funding for this work was provided by the National Heart, Lung and Blood Institute, Program Project Grant PO1 (HL074237).

\section{Reference list}

1. Stanley WC, Recchia FA, Lopaschuk GD. Myocardial substrate metabolism in the normal and failing heart. Physiological reviews. 2005 Jul; 85(3):1093-129. [PubMed: 15987803]

2. Barth AS, Kumordzie A, Frangakis C, Margulies KB, Cappola TP, Tomaselli GF. Reciprocal transcriptional regulation of metabolic and signaling pathways correlates with disease severity in heart failure. Circ Cardiovasc Genet. 2011 Oct; 4(5):475-83. [PubMed: 21828333]

3. Okita K, Yonezawa K, Nishijima H, Hanada A, Ohtsubo M, Kohya T, et al. Skeletal muscle metabolism limits exercise capacity in patients with chronic heart failure. Circulation. 1998 Nov 3; 98(18):1886-91. [PubMed: 9799209]

4. Stratton JR, Kemp GJ, Daly RC, Yacoub M, Rajagopalan B. Effects of cardiac transplantation on bioenergetic abnormalities of skeletal muscle in congestive heart failure. Circulation. 1994 Apr; 89(4):1624-31. [PubMed: 8149530]

5. Palmer JW, Tandler B, Hoppel CL. Biochemical differences between subsarcolemmal and interfibrillar mitochondria from rat cardiac muscle: effects of procedural manipulations. Archives of biochemistry and biophysics. 1985 Feb 1; 236(2):691-702. [PubMed: 2982322]

6. Hoppel CL, Tandler B, Fujioka H, Riva A. Dynamic organization of mitochondria in human heart and in myocardial disease. The international journal of biochemistry \& cell biology. 2009 Oct; 41(10):1949-56. [PubMed: 19446651]

7. Lukyanenko V, Chikando A, Lederer WJ. Mitochondria in cardiomyocyte Ca2+ signaling. The international journal of biochemistry \& cell biology. 2009 Oct; 41(10):1957-71. [PubMed: 19703657]

8. Tsyplenkova VG, Beskrovnova NN. The comparative morphological and morphometric characteristics of the myocardium in patients with a clinical diagnosis of hypertrophic cardiomyopathy. Arkhiv patologii. 1993 May-Jun;55(3):26-9. [PubMed: 7944964]

9. Takemura G, Takatsu Y, Sakaguchi H, Fujiwara H. Intranuclear mitochondria in human myocardial cells. Pathology, research and practice. 1997; 193(4):305-11.

10. Skulachev VP, Bakeeva LE, Chernyak BV, Domnina LV, Minin AA, Pletjushkina OY, et al. Thread-grain transition of mitochondrial reticulum as a step of mitoptosis and apoptosis. Molecular and cellular biochemistry. 2004 Jan-Feb;256-257(1-2):341-58.

11. Dabkowski ER, Williamson CL, Bukowski VC, Chapman RS, Leonard SS, Peer CJ, et al. Diabetic cardiomyopathy-associated dysfunction in spatially distinct mitochondrial subpopulations. American journal of physiology. 2009 Feb; 296(2):H359-69. [PubMed: 19060128] 
12. Riva A, Tandler B, Loffredo F, Vazquez E, Hoppel C. Structural differences in two biochemically defined populations of cardiac mitochondria. American journal of physiology. 2005 Aug; 289(2):H868-72. [PubMed: 15821034]

13. Kaasik A, Veksler V, Boehm E, Novotova M, Minajeva A, Ventura-Clapier R. Energetic crosstalk between organelles: architectural integration of energy production and utilization. Circulation research. 2001 Jul 20; 89(2):153-9. [PubMed: 11463722]

14. Su X, Sekiguchi M, Endo M. An ultrastructural study of cardiac myocytes in postmyocardial infarction ventricular aneurysm representative of chronic ischemic myocardium using semiquantitative and quantitative assessment. Cardiovasc Pathol. 2000 Jan-Feb;9(1):1-8. [PubMed: 10739901]

15. Coleman R, Silbermann M, Gershon D, Reznick AZ. Giant mitochondria in the myocardium of aging and endurance-trained mice. Gerontology. 1987; 33(1):34-9. [PubMed: 3596262]

16. Baandrup U, Florio RA, Roters F, Olsen EG. Electron microscopic investigation of endomyocardial biopsy samples in hypertrophy and cardiomyopathy. A semiquantitative study in 48 patients. Circulation. 1981 Jun; 63(6):1289-98. [PubMed: 6452971]

17. Sharov VG, Goussev A, Lesch M, Goldstein S, Sabbah HN. Abnormal mitochondrial function in myocardium of dogs with chronic heart failure. Journal of molecular and cellular cardiology. 1998 Sep; 30(9):1757-62. [PubMed: 9769231]

18. Taub PR, Ramirez-Sanchez I, Ciaraldi TP, Perkins G, Murphy AN, Naviaux R, et al. Alterations in skeletal muscle indicators of mitochondrial structure and biogenesis in patients with type 2 diabetes and heart failure: effects of epicatechin rich cocoa. Clinical and translational science. 2012 Feb; 5(1):43-7. [PubMed: 22376256]

19. Munzel T, Kurz S, Drexler H. Are alterations of skeletal muscle ultrastructure in patients with heart failure reversible under treatment with ACE-inhibitors? Herz. 1993 Dec; 18( Suppl 1):400-5.

20. Lai L, Leone TC, Zechner C, Schaeffer PJ, Kelly SM, Flanagan DP, et al. Transcriptional coactivators PGC-1alpha and PGC-lbeta control overlapping programs required for perinatal maturation of the heart. Genes \& development. 2008 Jul 15; 22(14):1948-61. [PubMed: 18628400]

21. Lehman JJ, Barger PM, Kovacs A, Saffitz JE, Medeiros DM, Kelly DP. Peroxisome proliferatoractivated receptor gamma coactivator-1 promotes cardiac mitochondrial biogenesis. The Journal of clinical investigation. 2000 Oct; 106(7):847-56. [PubMed: 11018072]

22. Garnier A, Fortin D, Zoll J, N'Guessan B, Mettauer B, Lampert E, et al. Coordinated changes in mitochondrial function and biogenesis in healthy and diseased human skeletal muscle. Faseb $\mathrm{J}$. 2005 Jan; 19(1):43-52. [PubMed: 15629894]

23. Toledo FG, Watkins S, Kelley DE. Changes induced by physical activity and weight loss in the morphology of intermyofibrillar mitochondria in obese men and women. The Journal of clinical endocrinology and metabolism. 2006 Aug; 91(8):3224-7. [PubMed: 16684829]

24. Ritov VB, Menshikova EV, He J, Ferrell RE, Goodpaster BH, Kelley DE. Deficiency of subsarcolemmal mitochondria in obesity and type 2 diabetes. Diabetes. 2005 Jan; 54(1):8-14. [PubMed: 15616005]

25. Iemitsu M, Miyauchi T, Maeda S, Sakai S, Fujii N, Miyazaki H, et al. Cardiac hypertrophy by hypertension and exercise training exhibits different gene expression of enzymes in energy metabolism. Hypertens Res. 2003 Oct; 26(10):829-37. [PubMed: 14621187]

26. Nishio ML, Ornatsky OI, Craig EE, Hood DA. Mitochondrial biogenesis during pressure overload induced cardiac hypertrophy in adult rats. Canadian journal of physiology and pharmacology. 1995 May; 73(5):630-7. [PubMed: 7585330]

27. Wang S, Fu C, Wang H, Shi Y, Xu X, Chen J, et al. Polymorphisms of the peroxisome proliferator-activated receptor-gamma coactivator-1alpha gene are associated with hypertrophic cardiomyopathy and not with hypertension hypertrophy. Clin Chem Lab Med. 2007; 45(8):962-7. [PubMed: 17579564]

28. Dai DF, Johnson SC, Villarin JJ, Chin MT, Nieves-Cintron M, Chen T, et al. Mitochondrial oxidative stress mediates angiotensin II-induced cardiac hypertrophy and Galphaq overexpressioninduced heart failure. Circulation research. 2011 Apr 1; 108(7):837-46. [PubMed: 21311045] 
29. Barger PM, Brandt JM, Leone TC, Weinheimer CJ, Kelly DP. Deactivation of peroxisome proliferator-activated receptor-alpha during cardiac hypertrophic growth. The Journal of clinical investigation. 2000 Jun; 105(12):1723-30. [PubMed: 10862787]

30. Garnier A, Fortin D, Delomenie C, Momken I, Veksler V, Ventura-Clapier R. Depressed mitochondrial transcription factors and oxidative capacity in rat failing cardiac and skeletal muscles. The Journal of physiology. 2003 Sep 1; 551(Pt 2):491-501. [PubMed: 12824444]

31. Gundewar S, Calvert JW, Jha S, Toedt-Pingel I, Ji SY, Nunez D, et al. Activation of AMPactivated protein kinase by metformin improves left ventricular function and survival in heart failure. Circulation research. 2009 Feb 13; 104(3):403-11. [PubMed: 19096023]

32. Tian R, Musi N, D’Agostino J, Hirshman MF, Goodyear LJ. Increased adenosine monophosphateactivated protein kinase activity in rat hearts with pressure-overload hypertrophy. Circulation. 2001 Oct 2; 104(14):1664-9. [PubMed: 11581146]

33. Scheubel RJ, Tostlebe M, Simm A, Rohrbach S, Prondzinsky R, Gellerich FN, et al. Dysfunction of mitochondrial respiratory chain complex I in human failing myocardium is not due to disturbed mitochondrial gene expression. Journal of the American College of Cardiology. 2002 Dec 18; 40(12):2174-81. [PubMed: 12505231]

34. Ventura-Clapier R, Garnier A, Veksler V. Energy metabolism in heart failure. The Journal of physiology. 2004 Feb 15; 555(Pt 1):1-13. [PubMed: 14660709]

35. Toth MJ, Miller MS, Ward KA, Ades PA. Skeletal Muscle Mitochondrial Density, Gene Expression and Enzyme Activities in Human Heart Failure: Minimal Effects of the Disease and Resistance Training. J Appl Physiol. 2012 Mar 29; 112(11):1864-74. [PubMed: 22461439]

36. Drexler H, Riede U, Munzel T, Konig H, Funke E, Just H. Alterations of skeletal muscle in chronic heart failure. Circulation. 1992 May; 85(5):1751-9. [PubMed: 1315220]

37. Ribera F, N'Guessan B, Zoll J, Fortin D, Serrurier B, Mettauer B, et al. Mitochondrial electron transport chain function is enhanced in inspiratory muscles of patients with chronic obstructive pulmonary disease. American journal of respiratory and critical care medicine. 2003 Mar 15; 167(6):873-9. [PubMed: 12493645]

38. Gosker HR, Hesselink MK, Duimel H, Ward KA, Schols AM. Reduced mitochondrial density in the vastus lateralis muscle of patients with COPD. Eur Respir J. 2007 Jul; 30(1):73-9. [PubMed: 17428811]

39. Picard M, Godin R, Sinnreich M, Baril J, Bourbeau J, Perrault H, et al. The mitochondrial phenotype of peripheral muscle in chronic obstructive pulmonary disease: disuse or dysfunction? American journal of respiratory and critical care medicine. 2008 Nov 15; 178(10):1040-7. [PubMed: 18755922]

40. Sebastiani M, Giordano C, Nediani C, Travaglini C, Borchi E, Zani M, et al. Induction of mitochondrial biogenesis is a maladaptive mechanism in mitochondrial cardiomyopathies. Journal of the American College of Cardiology. 2007 Oct 2; 50(14):1362-9. [PubMed: 17903636]

41. Graham BH, Waymire KG, Cottrell B, Trounce IA, MacGregor GR, Wallace DC. A mouse model for mitochondrial myopathy and cardiomyopathy resulting from a deficiency in the heart/muscle isoform of the adenine nucleotide translocator. Nature genetics. 1997 Jul; 16(3):226-34. [PubMed: 9207786]

42. Puccio H, Simon D, Cossee M, Criqui-Filipe P, Tiziano F, Melki J, et al. Mouse models for Friedreich ataxia exhibit cardiomyopathy, sensory nerve defect and Fe-S enzyme deficiency followed by intramitochondrial iron deposits. Nature genetics. $2001 \mathrm{Feb}$; 27(2):181-6. [PubMed: 11175786]

43. Li Y, Huang TT, Carlson EJ, Melov S, Ursell PC, Olson JL, et al. Dilated cardiomyopathy and neonatal lethality in mutant mice lacking manganese superoxide dismutase. Nature genetics. 1995 Dec; 11(4):376-81. [PubMed: 7493016]

44. Hansson A, Hance N, Dufour E, Rantanen A, Hultenby K, Clayton DA, et al. A switch in metabolism precedes increased mitochondrial biogenesis in respiratory chain-deficient mouse hearts. Proceedings of the National Academy of Sciences of the United States of America. 2004 Mar 2; 101(9):3136-41. [PubMed: 14978272] 
45. Ago T, Liu T, Zhai P, Chen W, Li H, Molkentin JD, et al. A redox-dependent pathway for regulating class II HDACs and cardiac hypertrophy. Cell. 2008 Jun 13; 133(6):978-93. [PubMed: $18555775]$

46. St-Pierre J, Drori S, Uldry M, Silvaggi JM, Rhee J, Jager S, et al. Suppression of reactive oxygen species and neurodegeneration by the PGC-1 transcriptional coactivators. Cell. 2006 Oct 20; 127(2):397-408. [PubMed: 17055439]

47. Zhang M, Brewer AC, Schroder K, Santos CX, Grieve DJ, Wang M, et al. NADPH oxidase-4 mediates protection against chronic load-induced stress in mouse hearts by enhancing angiogenesis. Proceedings of the National Academy of Sciences of the United States of America. 2010 Oct 19; 107(42):18121-6. [PubMed: 20921387]

48. Buchwald A, Till H, Unterberg C, Oberschmidt R, Figulla HR, Wiegand V. Alterations of the mitochondrial respiratory chain in human dilated cardiomyopathy. European heart journal. 1990 Jun; 11(6):509-16. [PubMed: 2161769]

49. Ide T, Tsutsui H, Kinugawa S, Utsumi H, Kang D, Hattori N, et al. Mitochondrial electron transport complex I is a potential source of oxygen free radicals in the failing myocardium. Circulation research. 1999 Aug 20; 85(4):357-63. [PubMed: 10455064]

50. Jarreta D, Orus J, Barrientos A, Miro O, Roig E, Heras M, et al. Mitochondrial function in heart muscle from patients with idiopathic dilated cardiomyopathy. Cardiovascular research. 2000 Mar; 45(4):860-5. [PubMed: 10728411]

51. Marin-Garcia J, Goldenthal MJ, Moe GW. Abnormal cardiac and skeletal muscle mitochondrial function in pacing-induced cardiac failure. Cardiovascular research. 2001 Oct; 52(1):103-10. [PubMed: 11557238]

52. Marin-Garcia J, Goldenthal MJ, Moe GW. Mitochondrial pathology in cardiac failure. Cardiovascular research. 2001 Jan; 49(1):17-26. [PubMed: 11121792]

53. Moe GW, Marin-Garcia J, Konig A, Goldenthal M, Lu X, Feng Q. In vivo TNF-alpha inhibition ameliorates cardiac mitochondrial dysfunction, oxidative stress, and apoptosis in experimental heart failure. American journal of physiology. 2004 Oct; 287(4):H1813-20. [PubMed: 15205165]

54. Heymes C, Bendall JK, Ratajczak P, Cave AC, Samuel JL, Hasenfuss G, et al. Increased myocardial NADPH oxidase activity in human heart failure. Journal of the American College of Cardiology. 2003 Jun 18; 41(12):2164-71. [PubMed: 12821241]

55. Kuroda J, Ago T, Matsushima S, Zhai P, Schneider MD, Sadoshima J. NADPH oxidase 4 (Nox4) is a major source of oxidative stress in the failing heart. Proceedings of the National Academy of Sciences of the United States of America. 2010 Aug 31; 107(35):15565-70. [PubMed: 20713697]

56. Palmer JW, Tandler B, Hoppel CL. Biochemical properties of subsarcolemmal and interfibrillar mitochondria isolated from rat cardiac muscle. The Journal of biological chemistry. 1977 Dec 10; 252(23):8731-9. [PubMed: 925018]

57. Fannin SW, Lesnefsky EJ, Slabe TJ, Hassan MO, Hoppel CL. Aging selectively decreases oxidative capacity in rat heart interfibrillar mitochondria. Archives of biochemistry and biophysics. 1999 Dec 15; 372(2):399-407. [PubMed: 10600182]

58. Hoppel CL, Tandler B, Parland W, Turkaly JS, Albers LD. Hamster cardiomyopathy. A defect in oxidative phosphorylation in the cardiac interfibrillar mitochondria. The Journal of biological chemistry. 1982 Feb 10; 257(3):1540-8. [PubMed: 6460026]

59. Weinstein ES, Benson DW, Fry DE. Subpopulations of human heart mitochondria. The Journal of surgical research. 1986 May; 40(5):495-8. [PubMed: 3736033]

60. Palmer JW, Tandler B, Hoppel CL. Heterogeneous response of subsarcolemmal heart mitochondria to calcium. The American journal of physiology. 1986 May; 250(5 Pt 2):H741-8. [PubMed: 3706549]

61. Duan J, Karmazyn M. Relationship between oxidative phosphorylation and adenine nucleotide translocase activity of two populations of cardiac mitochondria and mechanical recovery of ischemic hearts following reperfusion. Canadian journal of physiology and pharmacology. 1989 Jul; 67(7):704-9. [PubMed: 2548694]

62. Lesnefsky EJ, Tandler B, Ye J, Slabe TJ, Turkaly J, Hoppel CL. Myocardial ischemia decreases oxidative phosphorylation through cytochrome oxidase in subsarcolemmal mitochondria. The American journal of physiology. 1997 Sep; 273(3 Pt 2):H1544-54. [PubMed: 9321848] 
63. Lesnefsky EJ, Chen Q, Moghaddas S, Hassan MO, Tandler B, Hoppel CL. Blockade of electron transport during ischemia protects cardiac mitochondria. The Journal of biological chemistry. 2004 Nov 12; 279(46):47961-7. [PubMed: 15347666]

64. Hofer T, Servais S, Seo AY, Marzetti E, Hiona A, Upadhyay SJ, et al. Bioenergetics and permeability transition pore opening in heart subsarcolemmal and interfibrillar mitochondria: effects of aging and lifelong calorie restriction. Mechanisms of ageing and development. 2009 May; 130(5):297-307. [PubMed: 19428447]

65. Lesnefsky EJ, Gudz TI, Migita CT, Ikeda-Saito M, Hassan MO, Turkaly PJ, et al. Ischemic injury to mitochondrial electron transport in the aging heart: damage to the iron-sulfur protein subunit of electron transport complex III. Archives of biochemistry and biophysics. 2001 Jan 1; 385(1):11728. [PubMed: 11361007]

66. Judge S, Jang YM, Smith A, Hagen T, Leeuwenburgh C. Age-associated increases in oxidative stress and antioxidant enzyme activities in cardiac interfibrillar mitochondria: implications for the mitochondrial theory of aging. Faseb J. 2005 Mar; 19(3):419-21. [PubMed: 15642720]

67. Williamson CL, Dabkowski ER, Baseler WA, Croston TL, Alway SE, Hollander JM. Enhanced apoptotic propensity in diabetic cardiac mitochondria: influence of subcellular spatial location. American journal of physiology. 2010 Feb; 298(2):H633-42. [PubMed: 19966057]

68. Heather LC, Carr CA, Stuckey DJ, Pope S, Morten KJ, Carter EE, et al. Critical role of complex III in the early metabolic changes following myocardial infarction. Cardiovascular research. $2010 \mathrm{Jan}$ 1; 85(1):127-36. [PubMed: 19666902]

69. Sparagna GC, Chicco AJ, Murphy RC, Bristow MR, Johnson CA, Rees ML, et al. Loss of cardiac tetralinoleoyl cardiolipin in human and experimental heart failure. Journal of lipid research. 2007 Jul; 48(7):1559-70. [PubMed: 17426348]

70. Rosca MG, Vazquez EJ, Kerner J, Parland W, Chandler MP, Stanley W, et al. Cardiac mitochondria in heart failure: decrease in respirasomes and oxidative phosphorylation. Cardiovascular research. 2008 Oct 1; 80(1):30-9. [PubMed: 18710878]

71. Rosca M, Minkler P, Hoppel CL. Cardiac mitochondria in heart failure: normal cardiolipin profile and increased threonine phosphorylation of complex IV. Biochimica et biophysica acta. 2011 Nov; 1807(11):1373-82. [PubMed: 21320465]

72. Rosca MG, Okere IA, Sharma N, Stanley WC, Recchia FA, Hoppel CL. Altered expression of the adenine nucleotide translocase isoforms and decreased ATP synthase activity in skeletal muscle mitochondria in heart failure. Journal of molecular and cellular cardiology. 2009 Jun; 46(6):92735. [PubMed: 19233197]

73. Cogswell AM, Stevens RJ, Hood DA. Properties of skeletal muscle mitochondria isolated from subsarcolemmal and intermyofibrillar regions. The American journal of physiology. 1993 Feb; 264(2 Pt 1):C383-9. [PubMed: 8383431]

74. Takahashi M, Hood DA. Protein import into subsarcolemmal and intermyofibrillar skeletal muscle mitochondria. Differential import regulation in distinct subcellular regions. The Journal of biological chemistry. 1996 Nov 1; 271(44):27285-91. [PubMed: 8910303]

75. Adhihetty PJ, Ljubicic V, Hood DA. Effect of chronic contractile activity on SS and IMF mitochondrial apoptotic susceptibility in skeletal muscle. Am J Physiol Endocrinol Metab. 2007 Mar; 292(3):E748-55. [PubMed: 17106065]

76. Adhihetty PJ, Ljubicic V, Menzies KJ, Hood DA. Differential susceptibility of subsarcolemmal and intermyofibrillar mitochondria to apoptotic stimuli. Am J Physiol Cell Physiol. 2005 Oct; 289(4):C994-C1001. [PubMed: 15901602]

77. Shinde SB, Save VC, Patil ND, Mishra KP, Tendolkar AG. Impairment of mitochondrial respiratory chain enzyme activities in tetralogy of Fallot. Clinica chimica acta; international journal of clinical chemistry. 2007 Feb; 377(1-2):138-43.

78. Doenst T, Pytel G, Schrepper A, Amorim P, Farber G, Shingu Y, et al. Decreased rates of substrate oxidation ex vivo predict the onset of heart failure and contractile dysfunction in rats with pressure overload. Cardiovascular research. 2010 Jun 1; 86(3):461-70. [PubMed: 20035032]

79. Gong G, Liu J, Liang P, Guo T, Hu Q, Ochiai K, et al. Oxidative capacity in failing hearts. American journal of physiology. 2003 Aug; 285(2):H541-8. [PubMed: 12714322] 
80. Schrepper A, Schwarzer M, Schope M, Amorim PA, Doenst T. Biphasic response of skeletal muscle mitochondria to chronic cardiac pressure overload - role of respiratory chain complex activity. Journal of molecular and cellular cardiology. 2012 Jan; 52(1):125-35. [PubMed: 22100228]

81. Sanbe A, Tanonaka K, Niwano Y, Takeo S. Improvement of cardiac function and myocardial energy metabolism of rats with chronic heart failure by long-term coenzyme Q10 treatment. The Journal of pharmacology and experimental therapeutics. 1994 Apr; 269(1):51-6. [PubMed: 8169851]

82. Sharov VG, Todor AV, Silverman N, Goldstein S, Sabbah HN. Abnormal mitochondrial respiration in failed human myocardium. Journal of molecular and cellular cardiology. 2000 Dec; 32(12):2361-7. [PubMed: 11113011]

83. Sanbe A, Tanonaka K, Hanaoka Y, Katoh T, Takeo S. Regional energy metabolism of failing hearts following myocardial infarction. Journal of molecular and cellular cardiology. 1993 Sep; 25(9):995-1013. [PubMed: 8283476]

84. Lemieux H, Semsroth S, Antretter H, Hofer D, Gnaiger E. Mitochondrial respiratory control and early defects of oxidative phosphorylation in the failing human heart. The international journal of biochemistry \& cell biology. 2011 Dec; 43(12):1729-38. [PubMed: 21871578]

85. Lindenmayer GE, Sordahl LA, Schwartz A. Reevaluation of oxidative phosphorylation in cardiac mitochondria from normal animals and animals in heart failure. Circulation research. 1968 Sep; 23(3):439-50. [PubMed: 5676454]

86. Sordahl LA, McCollum WB, Wood WG, Schwartz A. Mitochondria and sarcoplasmic reticulum function in cardiac hypertrophy and failure. The American journal of physiology. 1973 Mar; 224(3):497-502. [PubMed: 4266238]

87. Lindenmayer GE, Harigaya S, Bajusz E, Schwartz A. Oxidative phosphorylation and calcium transport of mitochondria isolated from cardiomyopathic hamster hearts. Journal of molecular and cellular cardiology. 1970 Sep; 1(3):249-59. [PubMed: 5519939]

88. Wrogemann K, Blanchaer MC, Jacobson BE. Oxidative phosphorylation in cardiomyopathic hamsters. The American journal of physiology. 1972 Jun; 222(6):1453-7. [PubMed: 5030202]

89. Rosca MG, Vazquez EJ, Kerner J, Parland W, Chandler MP, Stanley W, et al. Cardiac mitochondria in heart failure: decrease in respirasomes and oxidative phosphorylation. Cardiovascular research. 2008 Aug 18; 80(1):30-9. [PubMed: 18710878]

90. Rosca MG, Hoppel CL. New aspects of impaired mitochondrial function in heart failure. Journal of bioenergetics and biomembranes. 2009 Apr; 41(2):107-12. [PubMed: 19347572]

91. Rosca MG, Hoppel CL. Mitochondria in heart failure. Cardiovascular research. 2010 Oct 1; 88(1): 40-50. [PubMed: 20668004]

92. Liu J, Wang C, Murakami Y, Gong G, Ishibashi Y, Prody C, et al. Mitochondrial ATPase and high-energy phosphates in failing hearts. American journal of physiology. $2001 \mathrm{Sep}$; 281(3):H1319-26. [PubMed: 11514303]

93. McCutcheon LJ, Cory CR, Nowack L, Shen H, Mirsalami M, Lahucky R, et al. Respiratory chain defect of myocardial mitochondria in idiopathic dilated cardiomyopathy of Doberman pinscher dogs. Canadian journal of physiology and pharmacology. 1992 Nov; 70(11):1529-33. [PubMed: 1338376]

94. Unverferth DV, Lee SW, Wallick ET. Human myocardial adenosine triphosphatase activities in health and heart failure. American heart journal. 1988 Jan; 115(1 Pt 1):139-46. [PubMed: 2827453]

95. Schultheiss HP, Bolte HD. Immunological analysis of auto-antibodies against the adenine nucleotide translocator in dilated cardiomyopathy. Journal of molecular and cellular cardiology. 1985 Jun; 17(6):603-17. [PubMed: 2991541]

96. Schultheiss HP. Dysfunction of the ADP/ATP carrier as a causative factor for the disturbance of the myocardial energy metabolism in dilated cardiomyopathy. Basic research in cardiology. 1992; 87( Suppl 1):311-20. [PubMed: 1497575]

97. Sylven C, Lin L, Jansson E, Sotonyi P, Fu LX, Waagstein F, et al. Ventricular adenine nucleotide translocator mRNA is upregulated in dilated cardiomyopathy. Cardiovascular research. $1993 \mathrm{Jul}$; 27(7):1295-9. [PubMed: 8252591] 
98. Dorner A, Schultheiss HP. The myocardial expression of the adenine nucleotide translocator isoforms is specifically altered in dilated cardiomyopathy. Herz. 2000 May; 25(3):176-80. [PubMed: 10904836]

99. Dorner A, Giessen S, Gaub R, Grosse Siestrup H, Schwimmbeck PL, Hetzer R, et al. An isoform shift in the cardiac adenine nucleotide translocase expression alters the kinetic properties of the carrier in dilated cardiomyopathy. Eur J Heart Fail. 2006 Jan; 8(1):81-9. [PubMed: 16107323]

100. Beyer K, Nuscher B. Specific cardiolipin binding interferes with labeling of sulfhydryl residues in the adenosine diphosphate/adenosine triphosphate carrier protein from beef heart mitochondria. Biochemistry. 1996 Dec 10; 35(49):15784-90. [PubMed: 8961941]

101. Ellis CE, Murphy EJ, Mitchell DC, Golovko MY, Scaglia F, Barcelo-Coblijn GC, et al. Mitochondrial lipid abnormality and electron transport chain impairment in mice lacking alphasynuclein. Molecular and cellular biology. 2005 Nov; 25(22):10190-201. [PubMed: 16260631]

102. Fry M, Green DE. Cardiolipin requirement by cytochrome oxidase and the catalytic role of phospholipid. Biochemical and biophysical research communications. 1980 Apr 29; 93(4):123846. [PubMed: 6249285]

103. Hoch FL. Cardiolipins and biomembrane function. Biochimica et biophysica acta. 1992 Mar 26; 1113(1):71-133. [PubMed: 1550861]

104. Hoch FL. Cardiolipins and mitochondrial proton-selective leakage. Journal of bioenergetics and biomembranes. 1998 Dec; 30(6):511-32. [PubMed: 10206472]

105. Nalecz KA, Bolli R, Wojtczak L, Azzi A. The monocarboxylate carrier from bovine heart mitochondria: partial purification and its substrate-transporting properties in a reconstituted system. Biochimica et biophysica acta. 1986 Aug 13; 851(1):29-37. [PubMed: 3730373]

106. Paradies G, Petrosillo G, Ruggiero FM. Cardiolipin-dependent decrease of cytochrome c oxidase activity in heart mitochondria from hypothyroid rats. Biochimica et biophysica acta. 1997 Mar 28; 1319(1):5-8. [PubMed: 9107312]

107. Pfeiffer K, Gohil V, Stuart RA, Hunte C, Brandt U, Greenberg ML, et al. Cardiolipin stabilizes respiratory chain supercomplexes. The Journal of biological chemistry. 2003 Dec 26; 278(52): 52873-80. [PubMed: 14561769]

108. Robinson NC. Functional binding of cardiolipin to cytochrome c oxidase. Journal of bioenergetics and biomembranes. 1993 Apr; 25(2):153-63. [PubMed: 8389748]

109. Schlame M, Rua D, Greenberg ML. The biosynthesis and functional role of cardiolipin. Progress in lipid research. 2000 May; 39(3):257-88. [PubMed: 10799718]

110. Tuominen EK, Wallace CJ, Kinnunen PK. Phospholipid-cytochrome c interaction: evidence for the extended lipid anchorage. The Journal of biological chemistry. 2002 Mar 15; 277(11):88226. [PubMed: 11781329]

111. Quigley AF, Kapsa RM, Esmore D, Hale G, Byrne E. Mitochondrial respiratory chain activity in idiopathic dilated cardiomyopathy. Journal of cardiac failure. 2000 Mar; 6(1):47-55. [PubMed: 10746819]

112. Dorner A, Pauschinger M, Schwimmbeck PL, Kuhl U, Schultheiss HP. The shift in the myocardial adenine nucleotide translocator isoform expression pattern is associated with an enteroviral infection in the absence of an active T-cell dependent immune response in human inflammatory heart disease. Journal of the American College of Cardiology. 2000 Jun; 35(7): 1778-84. [PubMed: 10841224]

113. Puchowicz MA, Varnes ME, Cohen BH, Friedman NR, Kerr DS, Hoppel CL. Oxidative phosphorylation analysis: assessing the integrated functional activity of human skeletal muscle mitochondria--case studies. Mitochondrion. 2004 Sep; 4(5-6):377-85. [PubMed: 16120399]

114. Faustin B, Rossignol R, Rocher C, Benard G, Malgat M, Letellier T. Mobilization of adenine nucleotide translocators as molecular bases of the biochemical threshold effect observed in mitochondrial diseases. The Journal of biological chemistry. 2004 May 7; 279(19):20411-21. [PubMed: 14976187]

115. Rossignol R, Malgat M, Mazat JP, Letellier T. Threshold effect and tissue specificity. Implication for mitochondrial cytopathies. The Journal of biological chemistry. 1999 Nov 19; 274(47): 33426-32. [PubMed: 10559224] 
116. Groen AK, Wanders RJ, Westerhoff HV, van der Meer R, Tager JM. Quantification of the contribution of various steps to the control of mitochondrial respiration. The Journal of biological chemistry. 1982 Mar 25; 257(6):2754-7. [PubMed: 7061448]

117. Gellerich FN, Bohnensack R, Kunz W. Control of mitochondrial respiration. The contribution of the adenine nucleotide translocator depends on the ATP- and ADP-consuming enzymes. Biochimica et biophysica acta. 1983 Feb 17; 722(2):381-91. [PubMed: 6301555]

118. Villani G, Attardi G. In vivo control of respiration by cytochrome c oxidase in human cells. Free radical biology \& medicine. 2000 Aug; 29(3-4):202-10. [PubMed: 11035248]

119. Kadenbach B, Huttemann M, Arnold S, Lee I, Bender E. Mitochondrial energy metabolism is regulated via nuclear-coded subunits of cytochrome c oxidase. Free radical biology \& medicine. 2000 Aug; 29(3-4):211-21. [PubMed: 11035249]

120. Xiao RP. Beta-adrenergic signaling in the heart: dual coupling of the beta2-adrenergic receptor to G(s) and G(i) proteins. Sci STKE. 2001 Oct.16(104):RE15. 2001. [PubMed: 11604549]

121. Bristow MR. beta-adrenergic receptor blockade in chronic heart failure. Circulation. 2000 Feb 8; 101(5):558-69. [PubMed: 10662755]

122. Hjalmarson A, Goldstein S, Fagerberg B, Wedel H, Waagstein F, Kjekshus J, et al. Effects of controlled-release metoprolol on total mortality, hospitalizations, and well-being in patients with heart failure: the Metoprolol CR/XL Randomized Intervention Trial in congestive heart failure (MERIT-HF). MERIT-HF Study Group. Jama. 2000 Mar 8; 283(10):1295-302. [PubMed: 10714728]

123. Bijur GN, Jope RS. Rapid accumulation of Akt in mitochondria following phosphatidylinositol 3 kinase activation. Journal of neurochemistry. 2003 Dec; 87(6):1427-35. [PubMed: 14713298]

124. Miura S, Kawanaka K, Kai Y, Tamura M, Goto M, Shiuchi T, et al. An increase in murine skeletal muscle peroxisome proliferator-activated receptor-gamma coactivator-1alpha (PGC-1alpha) mRNA in response to exercise is mediated by beta-adrenergic receptor activation. Endocrinology. 2007 Jul; 148(7):3441-8. [PubMed: 17446185]

125. Robinson MM, Richards JC, Hickey MS, Moore DR, Phillips SM, Bell C, et al. Acute \{beta $\}$ adrenergic stimulation does not alter mitochondrial protein synthesis or markers of mitochondrial biogenesis in adult men. Am J Physiol Regul Integr Comp Physiol. 2010 Jan; 298(1):R25-33. [PubMed: 19907002]

126. Benson DW, Foley-Nelson T, Chance WT, Zhang FS, James JH, Fischer JE. Decreased myofibrillar protein breakdown following treatment with clenbuterol. The Journal of surgical research. 1991 Jan; 50(1):1-5. [PubMed: 1670961]

127. Hoshino D, Yoshida Y, Holloway GP, Lally J, Hatta H, Bonen A. Clenbuterol, a beta2-adrenergic agonist, reciprocally alters PGC-1 alpha and RIP140 and reduces fatty acid and pyruvate oxidation in rat skeletal muscle. Am J Physiol Regul Integr Comp Physiol. 2012 Feb; 302(3):R373-84. [PubMed: 22071161]

128. Cooper DM, Mons N, Karpen JW. Adenylyl cyclases and the interaction between calcium and cAMP signalling. Nature. 1995 Mar 30; 374(6521):421-4. [PubMed: 7700350]

129. DiPilato LM, Cheng X, Zhang J. Fluorescent indicators of cAMP and Epac activation reveal differential dynamics of cAMP signaling within discrete subcellular compartments. Proceedings of the National Academy of Sciences of the United States of America. 2004 Nov 23; 101(47): 16513-8. [PubMed: 15545605]

130. Pagliarini DJ, Dixon JE. Mitochondrial modulation: reversible phosphorylation takes center stage? Trends in biochemical sciences. 2006 Jan; 31(1):26-34. [PubMed: 16337125]

131. Schwoch G, Trinczek B, Bode C. Localization of catalytic and regulatory subunits of cyclic AMP-dependent protein kinases in mitochondria from various rat tissues. The Biochemical journal. 1990 Aug 15; 270(1):181-8. [PubMed: 2396978]

132. Sardanelli AM, Technikova-Dobrova Z, Scacco SC, Speranza F, Papa S. Characterization of proteins phosphorylated by the cAMP-dependent protein kinase of bovine heart mitochondria. FEBS letters. 1995 Dec 27; 377(3):470-4. [PubMed: 8549778]

133. Sardanelli AM, Technikova-Dobrova Z, Speranza F, Mazzocca A, Scacco S, Papa S. Topology of the mitochondrial cAMP-dependent protein kinase and its substrates. FEBS letters. 1996 Nov 4; 396(2-3):276-8. [PubMed: 8915002] 
134. Acin-Perez R, Salazar E, Kamenetsky M, Buck J, Levin LR, Manfredi G. Cyclic AMP produced inside mitochondria regulates oxidative phosphorylation. Cell metabolism. 2009 Mar; 9(3):26576. [PubMed: 19254571]

135. Kawai K, Qin F, Shite J, Mao W, Fukuoka S, Liang CS. Importance of antioxidant and antiapoptotic effects of beta-receptor blockers in heart failure therapy. American journal of physiology. 2004 Sep; 287(3):H1003-12. [PubMed: 15105169]

136. Bartholomeu JB, Vanzelli AS, Rolim NP, Ferreira JC, Bechara LR, Tanaka LY, et al. Intracellular mechanisms of specific beta-adrenoceptor antagonists involved in improved cardiac function and survival in a genetic model of heart failure. Journal of molecular and cellular cardiology. 2008 Aug; 45(2):240-9. [PubMed: 18632114]

137. Nagatomo Y, Yoshikawa T, Kohno T, Yoshizawa A, Anzai T, Meguro T, et al. Effects of betablocker therapy on high sensitivity c-reactive protein, oxidative stress, and cardiac function in patients with congestive heart failure. Journal of cardiac failure. 2007 Jun; 13(5):365-71. [PubMed: 17602983]

138. Fedorova M, Kuleva N, Hoffmann R. Identification, quantification, and functional aspects of skeletal muscle protein-carbonylation in vivo during acute oxidative stress. Journal of proteome research. 2010 May 7; 9(5):2516-26. [PubMed: 20377239]

139. Costa VM, Silva R, Ferreira R, Amado F, Carvalho F, de Lourdes Bastos M, et al. Adrenaline in pro-oxidant conditions elicits intracellular survival pathways in isolated rat cardiomyocytes. Toxicology. 2009 Mar 4; 257(1-2):70-9. [PubMed: 19135123]

140. Yamada T, Mishima T, Sakamoto M, Sugiyama M, Matsunaga S, Wada M. Myofibrillar protein oxidation and contractile dysfunction in hyperthyroid rat diaphragm. J Appl Physiol. 2007 May; 102(5):1850-5. [PubMed: 17303704]

141. Zhao W, Swanson SA, Ye J, Li X, Shelton JM, Zhang W, et al. Reactive oxygen species impair sympathetic vasoregulation in skeletal muscle in angiotensin II-dependent hypertension. Hypertension. 2006 Oct; 48(4):637-43. [PubMed: 16940212]

142. Wei Y, Sowers JR, Nistala R, Gong H, Uptergrove GM, Clark SE, et al. Angiotensin II-induced NADPH oxidase activation impairs insulin signaling in skeletal muscle cells. The Journal of biological chemistry. 2006 Nov 17; 281(46):35137-46. [PubMed: 16982630]

143. Semprun-Prieto LC, Sukhanov S, Yoshida T, Rezk BM, Gonzalez-Villalobos RA, Vaughn C, et al. Angiotensin II induced catabolic effect and muscle atrophy are redox dependent. Biochemical and biophysical research communications. 2011 Jun 3; 409(2):217-21. [PubMed: 21570954]

144. Kimura S, Zhang GX, Nishiyama A, Shokoji T, Yao L, Fan YY, et al. Role of NAD(P)H oxidaseand mitochondria-derived reactive oxygen species in cardioprotection of ischemic reperfusion injury by angiotensin II. Hypertension. 2005 May; 45(5):860-6. [PubMed: 15824196]

145. Brink M, Wellen J, Delafontaine P. Angiotensin II causes weight loss and decreases circulating insulin-like growth factor I in rats through a pressor-independent mechanism. The Journal of clinical investigation. 1996 Jun 1; 97(11):2509-16. [PubMed: 8647943]

146. Thaveau F, Zoll J, Bouitbir J, N'Guessan B, Plobner P, Chakfe N, et al. Effect of chronic pretreatment with angiotensin converting enzyme inhibition on skeletal muscle mitochondrial recovery after ischemia/reperfusion. Fundamental \& clinical pharmacology. 2010 Jun; 24(3): 333-40. [PubMed: 19682081]

147. van Kimmenade RR, Januzzi JL Jr. Emerging biomarkers in heart failure. Clinical chemistry. 2012 Jan; 58(1):127-38. [PubMed: 22086968]

148. Fischer P, Hilfiker-Kleiner D. Survival pathways in hypertrophy and heart failure: the gp130STAT axis. Basic research in cardiology. 2007 Sep; 102(5):393-411. [PubMed: 17918316]

149. Smart N, Mojet MH, Latchman DS, Marber MS, Duchen MR, Heads RJ. IL-6 induces PI 3kinase and nitric oxide-dependent protection and preserves mitochondrial function in cardiomyocytes. Cardiovascular research. 2006 Jan; 69(1):164-77. [PubMed: 16219301]

150. Szczepanek K, Chen Q, Derecka M, Salloum FN, Zhang Q, Szelag M, et al. Mitochondrialtargeted Signal transducer and activator of transcription 3 (STAT3) protects against ischemiainduced changes in the electron transport chain and the generation of reactive oxygen species. The Journal of biological chemistry. 2011 Aug 26; 286(34):29610-20. [PubMed: 21715323] 
151. Bozkurt B, Kribbs SB, Clubb FJ Jr, Michael LH, Didenko VV, Hornsby PJ, et al. Pathophysiologically relevant concentrations of tumor necrosis factor-alpha promote progressive left ventricular dysfunction and remodeling in rats. Circulation. 1998 Apr 14; 97(14):1382-91. [PubMed: 9577950]

152. Ozcan C, Bienengraeber M, Hodgson DM, Mann DL, Terzic A. Mitochondrial tolerance to stress impaired in failing heart. Journal of molecular and cellular cardiology. 2003 Sep; 35(9):1161-6. [PubMed: 12967639]

153. Nakamura K, Fushimi K, Kouchi H, Mihara K, Miyazaki M, Ohe T, et al. Inhibitory effects of antioxidants on neonatal rat cardiac myocyte hypertrophy induced by tumor necrosis factor-alpha and angiotensin II. Circulation. 1998 Aug 25; 98(8):794-9. [PubMed: 9727550]

154. Suematsu N, Tsutsui H, Wen J, Kang D, Ikeuchi M, Ide T, et al. Oxidative stress mediates tumor necrosis factor-alpha-induced mitochondrial DNA damage and dysfunction in cardiac myocytes. Circulation. 2003 Mar 18; 107(10):1418-23. [PubMed: 12642364]

155. Song W, Lu X, Feng Q. Tumor necrosis factor-alpha induces apoptosis via inducible nitric oxide synthase in neonatal mouse cardiomyocytes. Cardiovascular research. 2000 Feb; 45(3):595-602. [PubMed: 10728381] 


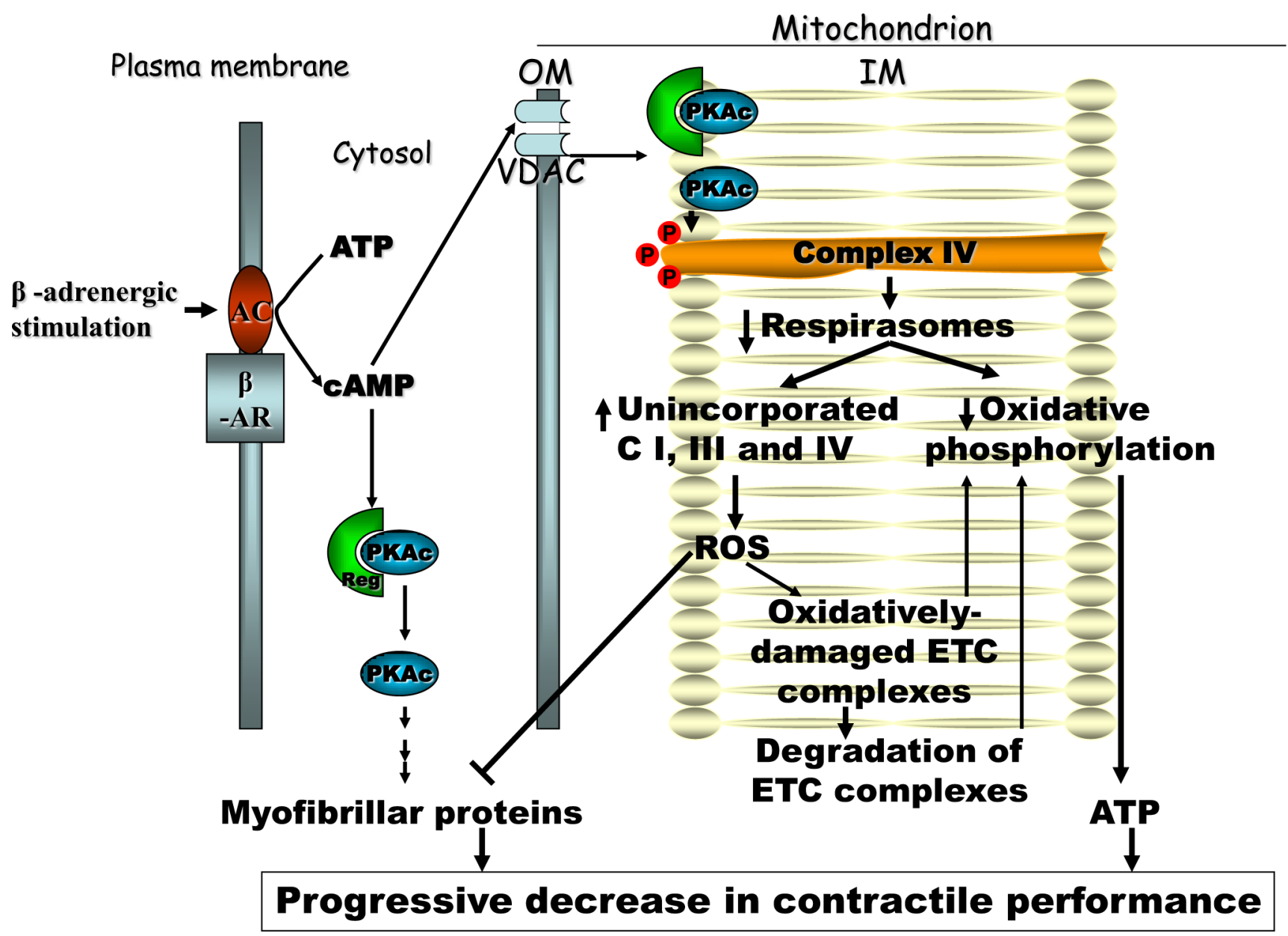

Figure 1.

Potential mechanism by which increased adrenergic drive induces bioenergetic failure in heart failure 